\title{
APLIKASI PERBAIKAN AKTA KELAHIRAN DAN SMS GATEWAY BERBASIS WEB PADA DINAS KEPENDUDUKAN DAN PENCATATAN SIPIL KABUPATEN KARAWANG
}

\author{
Rahmat Gunawan ${ }^{1}$, Arif Maulana Yusuf ${ }^{2}$, Nasrudin $^{3}$ \\ ${ }^{123}$ STMIK Rosma \\ 'rahmat@rosma.ac.id, 2arif@rosma.ac.id, 33nasrudin@mhs.rosma.ac.id
}

Jl. Kertabumi No.62, Karawang Kulon, Kec. Karawang Bar., Kabupaten Karawang, Jawa Barat 41311

\begin{abstract}
Abstrak_ Perkembangan teknologi informasi yang sangat berkembang pesat mampu memberikan dampak yang cukup besar bagi semua sektor, tidak terkecuali sektor pemerintahan dalam bidang pelayanan publik. Dinas kependudukan dan pencatatan sipil Kabupaten Karawang, Disdukcatpil Karawang dalam proses perbaikan akta kelahiran kesulitan mendata permohonan perbaikan akta kelahiran yang jatuh tempo pada saat pengambilan, karena proses pendataan perbaikan masih dilakukan manual, tidak hanya itu ketika permohonan perbaikan di pending oleh pejabat terkait petugas kesulitan memberikan informasi kepada pemohon apa saja yang harus di lengkapi. Dari permasalahan tersebut penulis mengajukan solusi untuk memperbaiki sistem perbaikan akta kelahiran pada Disdukcatpil karawang menjadi terkomputerisasi dan terintegrasi dengan SMS Gateway, sehingga masalah yang terjadi dapat teratasi dengan baik dan dapat meningkatkan mutu pelayanan perbaikan akta kelahiran. Perancangan perbaikan akta kelahiran ini memberikan dampak yang positif terhadap kinerja pegawai dan memberikan informasi yang cepat kepada masyarakat yang memperbaiki akta kelahiran dengan fitur aplikasi meliputi pendataan pemohon, pendataan permohonan, SMS Gateway, serta pembuatan laporan.
\end{abstract}

Kata Kunci_-SMS Gateway, website, Dinas kependudukan dan pencatatan sipil, akta kelahiran, pelayanan publik,

Abstract - The development of information technology that is growing rapidly is able to have a considerable impact on all sectors, including the government sector in the field of public services. The Population and Civil Registration Office of Karawang Regency, Disdukcatpil Karawang in the process of repairing birth certificates has difficulty registering requests for repair of birth certificates that are due at the time of collection, because the repair data collection process is still done manually, not only that when the request for repair is pending by officials related to the officer, it is difficult to provide information to the applicant what must be completed. From these problems the authors propose a solution to improve the birth certificate repair system at Disdukcatpil Karawang to be computerized and integrated with the SMS Gateway, so that problems that occur can be resolved properly and can improve the quality of birth certificate repair services. This birth certificate repair design has a positive impact on employee performance and provides quick information to the public who repair birth certificates with application features including applicant data collection, application data collection, SMS Gateway, and report generation.

Keywords - SMS Gateway, website, Department of Population and Civil Registration, Public Service.

\section{PENDAHULUAN}

Pada era modern ini perkembangan teknologi informasi sangat berkembang pesat dan mampu memberikan efek yang cukup besar bagi semua sektor usaha, apalagi dalam bidang pelayanan publik, ketepatan dan kecepatan pelayanan itu sangat penting dalam pelayanan publik, penggunaan aplikasi berbasis web dirasa mampu memberikan kemudahan dalam pelayanan publik.

Dinas Kependudukan dan Pencatatan Sipil Kabupaten Karawang adalah salah satu instansi pemerintah sebagai penyelenggara pelayanan publik di daerah, Sesuai dengan Peraturan Daerah Kabupaten Karawang Nomor 6 Tahun 2014 tentang Pembentukan Sekretariat Daerah, Sekretariat DPRD, Dinas Daerah dan Lembaga Teknis Daerah, Kecamatan dan Kelurahan, dan Sesuai dengan Peraturan Daerah Kabupaten Karawang Nomor 14 Tahun 2016 tentang Pembentukan dan Susunan Perangkat Daerah Kabupaten Karawang dan Peraturan Bupati Karawang Nomor 52 Tahun 2016.

Kendala yang dihadapi petugas dalam melayani permohonan perbaikan Akta kelahiran adalah pembuatan laporan bulanan yang masih menggunakan perhitungan manual dengan Microsoft Excel dan informasi perbaikan akta kelahiran yang diberikan 
kepada masyarakat sangat lambat karena informasi disampaikan dari pencatatan sipil melalui ketua RT. Pendataan permohonan yang jatuh tempo saat ini dan pemberitahuan kepada pemohon jika persyaratan yang diajukan pemohon ada kekurangan/ permohonan Page|222 perubahan data Akta kelahiran tidak disetujui oleh pejabat Pencatatan Sipil dan pemberitahuan jika Akta kelahiran sudah selesai di ajukan dan bisa diambil oleh pemohon. Untuk gambaran detail dari permasalahan dituangkan pada sistem berjalan.

Berdasarkan uraian masalah diatas penulis berencana mengambil suatu solusi untuk menyelesaikan masalah dengan Langkah sesuai metode penelitian Design Science Research Methodology agar dapat memberikan hasil yang bermanfaat dan memberikan solusi dari permasalahan yang terjadi pada tempat penelitian.

\section{TINJAUAN PUSTAKA}

Sistem adalah kumpulan orang yang saling bekerja sama dengan ketentuan-ketentuan aturan yang sistematis dan terstruktur untuk membentuk satu kesatuan yang melaksanakan suatu fungsi untuk mencapai tujuan, sistem memiliki beberapa karakteristik atau sifat yang terdiri dari komponen sistem, batasan sistem, lingkungan luar sistem, penghubung sistem, masukan sistem, keluaran sistem pengolahan sistem dan sasaran sistem[1].

Sedangkan informasi adalah data yang diolah menjadi lebih berguna dan berarti bagi penerimanya, serta untuk mengurangi ketidakpastian dalam proses pengambilan keputusan mengenai suatu keadaan , sistem informasi merupakan suatu kombinasi teratur dari orang-orang hardware, software, jaringan komunikasi dan sumber daya data yang mengumpulkan, mengubah, dan menyebarkan informasi dalam sebuah organisasi[1].

Sistem informasi yaitu sistem yang menyediakan informasi untuk manajemen dalam mengambil keputusan dan juga menjalankan operasional perusahaan, dimana sistem tersebut merupakan kombinasi dari orang-orang . teknologi informasi dan prosedur-prosedur yang terorganisasi, biasanya suatu perusahaan atau badan usaha menyediakan semacam informasi yang berguna bagi manajemen.

Website adalah salah satu aplikasi yang berisikan dokumen-dokumen multimedia seperti (teks, gambar, suara, animasi, video) di dalamnya yang menggunakan protokol HTTP (Hypertext Transfer Protocol) dan untuk mengaksesnya menggunakan perangkat lunak yang disebut browser[2].

Web server adalah sebuah program yang menggunakan client/server dan World Wide Web Hypertext Transfer Protocol(HTTP) dan melayani file yang membentuk halaman web untuk pengguna web atau memberi konten atau layanan kepada pengguna akhir melalui internet[2].

XAMPP adalah web server apache yang sepenuhnya gratis, mudah dipasang, distribusi yang berisi mysql, php, dan perl, paket sumber terbuka xampp telah diatur agar sangat mudah dipasang dan digunakan[2].

Apache adalah HTTP Server Project yang merupakan upaya untuk mengembangkan dan mempertahankan server HTTP open-source untuk sistem operasi modern termasuk UNIX dan Windows NT. Tujuan dari proyek ini adalah untuk memberikan aman, efisien dan extensible server yang menyediakan layanan HTTP sinkron dengan standar HTTP saat ini[2].

PHP singkatan dari "Hypertext Preprocessor" dan PHP merupakan bahasa pemrograman skrip yang dirancang untuk membangun aplikasi web. Ketika dipanggil dari web browser, program yang ditulis dengan PHP akan di parsing di dalam web server oleh interpreter PHP dan diterjemahkan ke dalam dokumen HTML, yang selanjutnya akan ditampilkan kembali ke web browser. Karena pemrosesan program PHP dilakukan dilingkungan web server, PHP dikatakan sebagai bahasa sisi server (server side). Oleh sebab itu, kode PHP tidak akan terlihat pada saat user memilih perintah "view source" pada web browser yang mereka gunakan[3].

\section{SMS Gateway}

SMS Gateway adalah suatu aplikasi yang memungkinkan kita untuk menerima atau mengirim sms, sebagai pengganti perangkat telekomunikasi (handphone, modem), ketika kita menerima/mengirim sms, maka kita akan memakai fungsi dan tomboltombol yang ada pada handphone[4].

\section{Entity relationship Diagram}

Merupakan sebuah teknik pemodelan data yang mempresentasikan gambar entitas dan relasi-relasi antara entitas di dalam sebuah informasi. ERD dibentuk oleh dua komponen, yaitu:

1. Entity (entity) : merupakan suatu objek yang mewakili sesuatu dalam dunia nyata, baik secara fisik maupun secara konsep.

2. Relasi (relationship) : menyatakan hubungan antara entitas termasuk entitas itu sendiri.

\section{Unified Modeling Language}

UML (Unified Modeling Language) adalah bahasa standar yang digunakan untuk di dunia industri untuk mendefinisikan requirement, membuat analisa dan desain serta menggambarkan arsitektur dalam pemrograman berorientasi objek.

\section{Black box Tesing}

Black-box testing atau yang biasa dikenal sebagai behavioral testing adalah proses pengujian yang berfokus requirement (persyaratan) fungsional dari perangkat lunak. Black-box testing memungkinkan developer untuk mendapatkan set kondisi input yang sepenuhnya melaksanakan semua requirement 
(persyaratan) fungsional suatu program (perangkat lunak)[5].

\section{METODE PENELITIAN}

Page | 223

Metode penelitian yang digunakan dalam penelitian ini menggunakan Design Science Research Methodology (DSRM). Penggunaan metodologi ini difokuskan pada solusi permasalahan dan pengembangan sistem, metodologi DSRM dikenalkan pertama kali oleh Ken Peffers, Marcus A. Rothenberger, dan Samir Saterjee, pada jurnal ilmiah mereka yang berjudul A Design Science Research Methodology For Information System Research. [6] [7]

\section{Langkah-langkah penelitian}

Berikut tahapan-tahapan dari metodologi penelitian Design Science Research Methodology (DSRM)

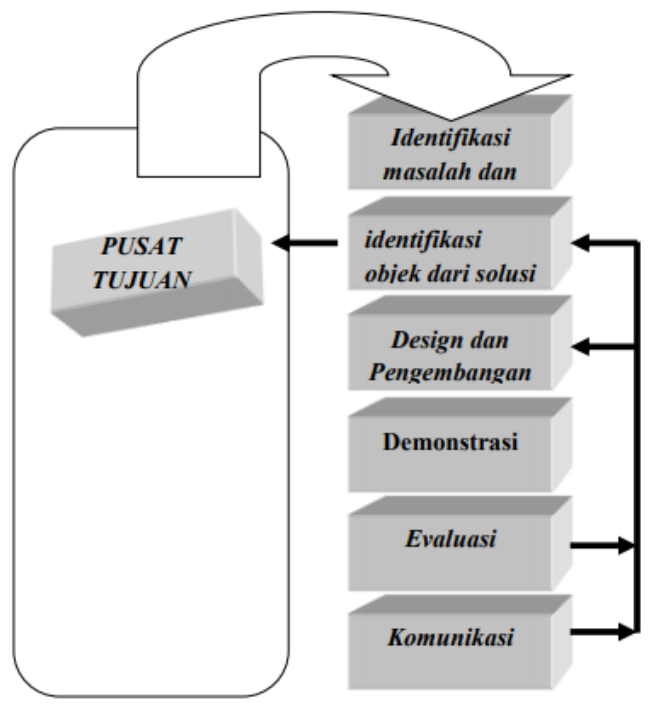

Gbr. 1 Langkah-langkah Penelitian

\section{Identifikasi masalah dan motivasi}

Pada tahapan ini kita bisa mengidentifikasi semua masalah-masalah yang ada pada proses pelayanan perbaikan akta kelahiran di Dinas kependudukan dan Pencatatan Sipil Kabupaten Karawang, serta mendefinisikan masalah yang akan digunakan untuk selanjutnya dibuat sebuah program efektif yang dapat memberikan solusi secara menyeluruh.

Proses identifikasi masalah dilakukan pada bagian pelayanan perbaikan akta kelahiran dengan melakukan pengumpulan data dengan cara:

\section{A. Observasi}

Peneliti memposisikan diri sebagai pengamat dan ikut berperan serta, sehingga observasi dilakukan dengan pengamatan secara langsung di Dinas Kependudukan dan Pencatatan Sipil Kabupaten Karawang.

\section{B. Wawancara}

Wawancara merupakan salah satu bentuk teknik pengumpulan data dengan melalui tanya jawab dengan dengan pejabat bidang pencatatan sipil serta staff bidang pencatatan sipil Dinas Kependudukan dan Pencatatan Sipil Kabupaten Karawang, percakapan dengan maksud tertentu. Metode wawancara digunakan guna memperoleh keterangan tentang kejadian yang oleh peneliti tidak dapat diamati sendiri secara langsung, baik itu terjadi di masa lampau ataupun karena tidak memungkinkan untuk hadir di tempat kejadian.

\section{Mendefinisikan obyek dari solusi permasalahan}

Setelah proses identifikasi masalah didapatkan dengan menghasilkan output berupa beberapa masalah yang sedang dihadapi bagian perbaikan akta kelahiran Dinas Kependudukan dan Pencatatan Sipil Kabupaten Karawang maka dibuat solusi dari permasalahan tersebut. Untuk mencari solusi dari permasalahan yang didapat, terlebih dahulu dilakukan pendefinisian masalah dengan melakukan aktifitas wawancara dengan staff perbaikan akta kelahiran dengan cara Focus Group Discussion (FGD) dengan pejabat pencatatan sipil Dinas Kependudukan dan Pencatatan Sipil Kabupaten Karawang. Hasil dari Focus Group Discussion ini berupa kesimpulan untuk menjelaskan tujuan dari solusi, definisi masalah, serta pengetahuan tentang apa yang mungkin dan layak untuk dijadikan solusi. Tentunya solusi yang diinginkan akan lebih baik dari yang sekarang, atau bagaimana solusi baru ini diharapkan bisa mendukung penyelesaian masalah yang sekarang ditangani secara rasional.

\section{Desain dan Pengembangan}

Setelah mendapatkan solusi dengan melakukan Focus Group Discussion (FGD) dengan staff dan Pejabat pencatatan sipil, kemudian peneliti membuat desain berupa rancangan dan model dari analisa yang dilakukan pada tahap sebelumnya, selanjutnya akan dilakukan pengembangan dengan model Unified Modelling Language (UML) untuk proses logika sistem, dalam penelitian ini hanya satu diagram yang akan digambarkan yaitu Activity Diagram.

\section{Demonstrasi (implementasi)}

Pada tahap ini peneliti melakukan implementasi terhadap rancangan pengembangan, tahap ini merupakan tahap pengkodingan menggunakan Visual Studio Code sebagai teks editor dan XAMPP sebagai webserver.

\section{Evaluasi}

Hasil pengamatan dan evaluasi sistem dilakukan oleh pihak staff perbaikan akta kelahiran Dinas Kependudukan dan Pencatatan Sipil Kabupaten Karawang, apakah sistem sudah sesuai yang diharapkan atau belum, serta mengamati dan mengukur seberapa 
baik solusi ini untuk menyelesaikan masalah yang ada. Setelah memberikan penilaian berupa kendala-kendala yang dihadapi saat menggunakan program ini, serta masalah-masalah yang muncul nantinya.

\section{Komunikasi}

Naskah yang berkaitan dengan dengan masalah dan solusi diatas di dokumentasikan dan dijadikan laporan sebagai hasil penelitian ilmiah kemudian diterapkan pada pelayanan perbaikan akta kelahiran Dinas Kependudukan dan Pencatatan Sipil Kabupaten Karawang.

\section{HASIL DAN PEMBAHASAN}

\section{Usulan Hardware/Software}

Untuk menunjang kelancaran sistem yang dirancang, diperlukan hardware dan software yang tepat dan dapat menjalankan sistem pelayanan Akta Kelahiran yang baik serta dapat memberikan informasi kepada masyarakat tentang permasalahan Akta Kelahiran yang terjadi. Adapun hardware yang diusulkan penulis adalah :

1. Monitor VGA 14"

2. Prosessor minimal Intel Core I5-8250U

3. RAM 4 GB minimal

4. Harddisk $500 \mathrm{~GB}$

5. Mouse dan Keyboard

6. Printer EPSON L360

Selain hardware di atas, juga di butuhkan software atau aplikasi yang dapat menjalankan kinerja sistem. Usulan software yang digunakan sebagai berikut :

1. Sistem Operasi (Microsoft Windows/Linux/Mac OS)

2. Web Browser

3. XAMPP

\section{Usulan Tenaga kerja}

Tenaga kerja merupakan faktor penting dalam menunjang Kinerja pelayanan masyarakat yang cepat dan keakuratan informasi, karena suatu sistem tanpa tenaga kerja yang mampu menjalankan sistem tersebut tidak akan berjalan sesuai dengan yang di harapkan. Akan tetapi, tenaga kerja juga harus disesuaikan dengan kemampuannya dalam penempatan bidang pekerjaannya. Adapun usulan tenaga kerjanya untuk Programmer satu orang, Admin satu orang, dan Operator dua orang.

\section{Usulan sistem baru}

Dalam sistem usulan yang penulis usulkan, diharapkan dapat menemui titik sasaran atau informasi yang dapat membantu proses kegiatan kerja yang berjalan dan mengatasi kerancuan informasi bagi masyarakat mengenai perbaikan Akta Kelahiran. Adapun sasaran atau informasi yang dapat penulis usulkan yaitu :
1. Memberikan informasi yang jelas kepada pemohon perbaikan Akta kelahiran tentang status permohonannya.

2. Mempermudah petugas perbaikan Akta Kelahiran dalam pencarian data permohonan perbaikan Akta Kelahiran

\section{Deskripsi Sistem Yang Diusulkan}

Berdasarkan hasil analisa penulis maka sistem yang telah berjalan pada Dinas Kependudukan dan Pencatatan Sipil akan dirancang dan dibangun menjadi sistem yang terkomputerisasi berbasis website Sehingga dapat mengolah dan memproses data tentang pelayanan perbaikan akta kelahiran dengan cepat dan dapat menghasilkan informasi yang akurat sesuai dengan kebutuhan dan akan memperkaya interface sistem serta akan mempermudah dalam pengoperasiannya.

\section{Perancangan Sistem Usulan}

Pada perancangan sistem yang penulis usulkan tidak ada perubahan secara signifikan, hanya ada perubahan terutama dalam proses komputerisasi pada bagian pelayanan perbaikan akta kelahiran, perubahan tersebut dilihat pada gambar 1 Flow Of Document pelayanan perbaikan akta kelahiran pada Dinas Kependudukan dan Pencatatan Sipil Kabupaten Karawang.

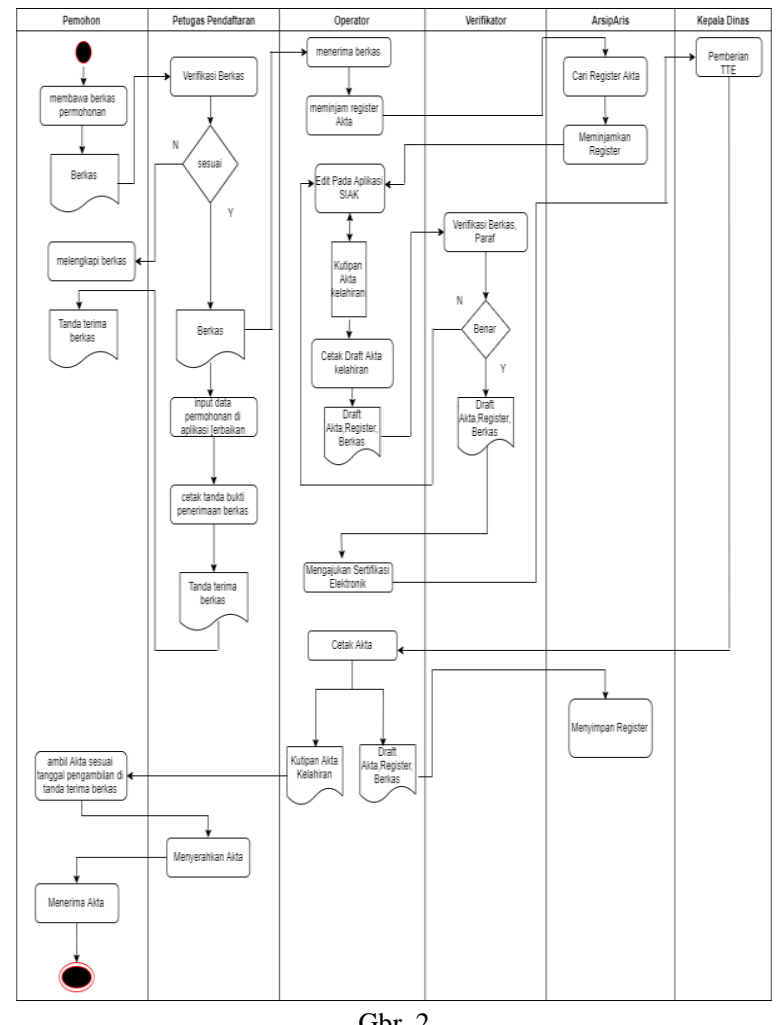

Flow Of Document pelayanan perbaikan akta kelahiran pada Dinas Kependudukan dan Pencatatan Sipil Kabupaten Karawang 
Implementasi Rancangan antarmuka

1. Halaman Login

Halaman login digunakan untuk masuk dan mengakses aplikasi.

Page | 225

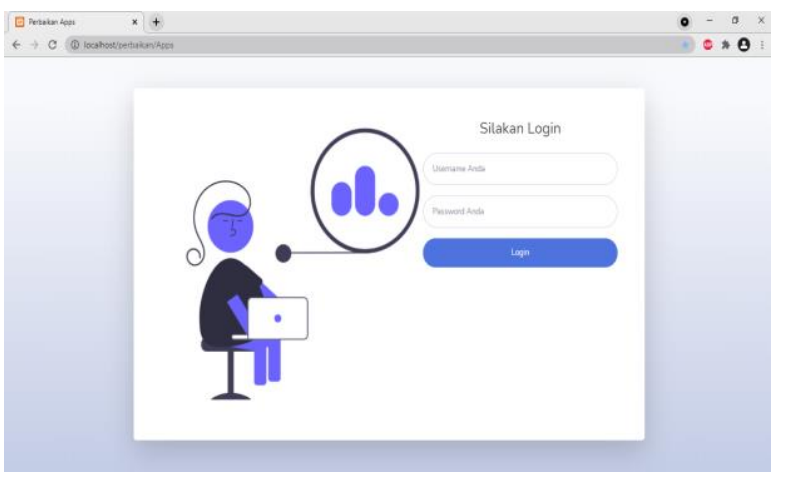

Gbr. 3 Halaman Login

2. Halaman Dashboard

Halaman dashboard halaman pertama kali di akses pengguna ketika berhasil login

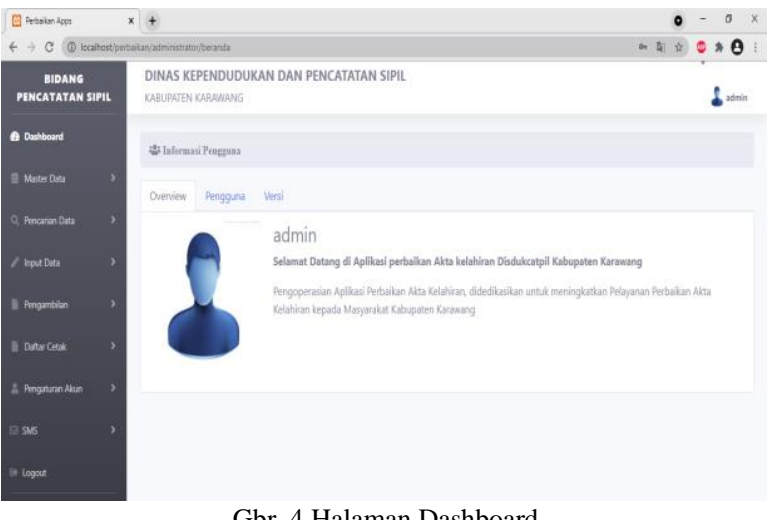

Gbr. 4 Halaman Dashboard

3. Halaman input master pemohon

Halaman input master pemohon digunakan untuk menambah data master pemohon

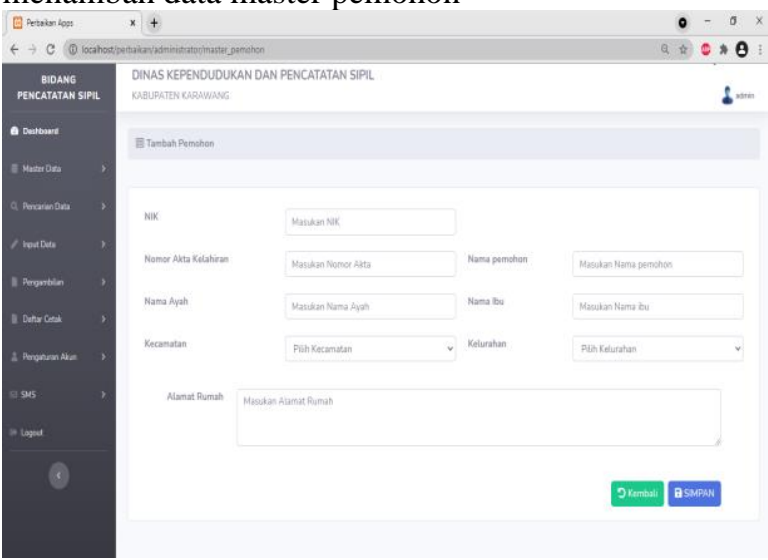

Gbr. 5 Halaman input master pemohon

4. Halaman input permohonan

Halaman input permohonan digunakan untuk menambah data permohonan

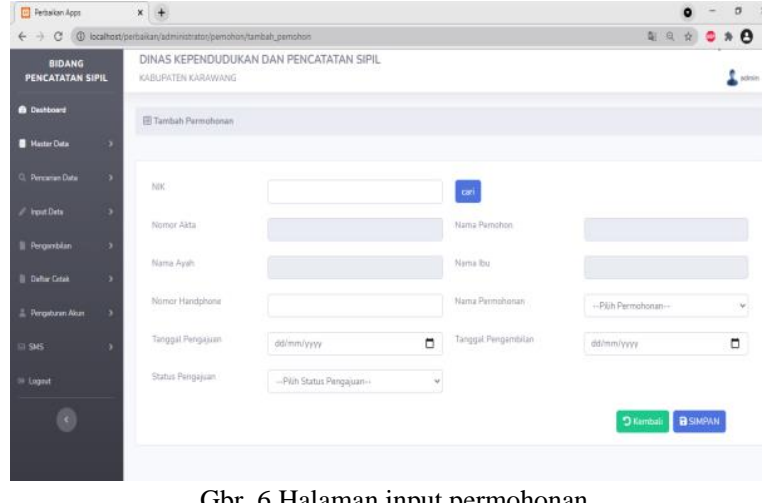

5. Halaman input Pengambilan

Halaman input pengambilan digunakan untuk menambah data pengambilan

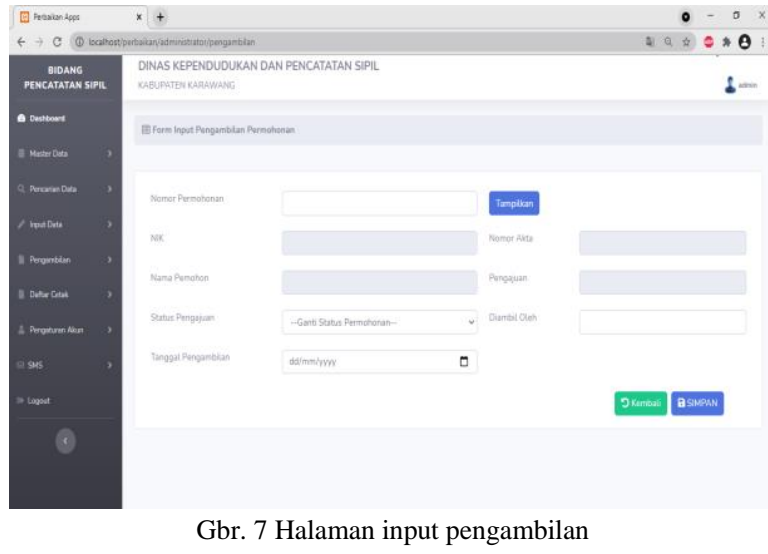

6. Halaman Daftar cetak resi

Halaman daftar cetak resi digunakan untuk mencari daftar resi permohonan

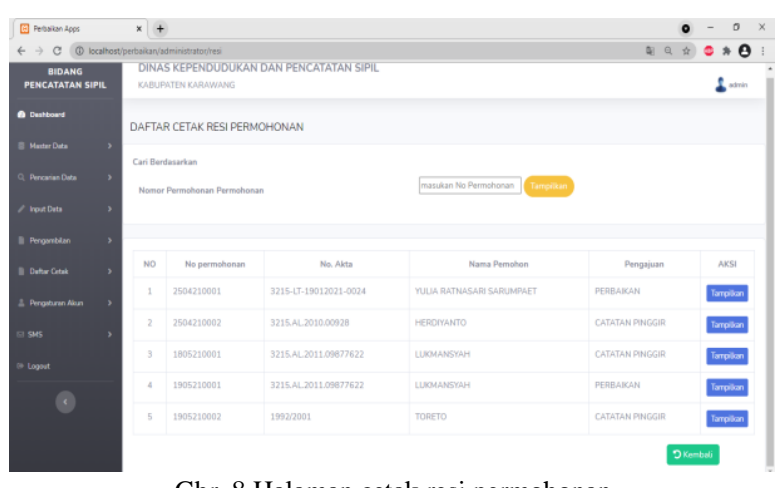

Gbr. 8 Halaman cetak resi permohonan

7. Halaman filter laporan permohonan Halaman filter laporan permohonan digunakan untuk memfilter laporan permohonan berdasarkan tanggal bulan dan tahun 

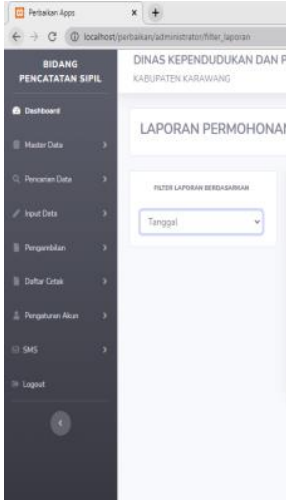

Gbr. 9 Halaman filter laporan permohonan

8. Halaman filter laporan pengambilan Halaman filter laporan pengambilan digunakan untuk memfilter data laporan pengambilan berdasarkan tanggal bulan dan tahun

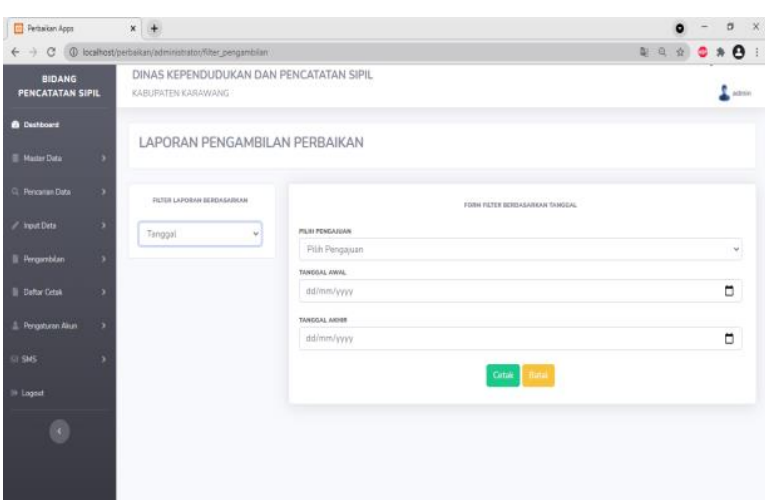

Gbr. 10 Halaman filter laporan pengambilan

9. Halaman kirim SMS

Halaman kirim SMS digunakan untuk mengirimkan pesan SMS kepada pemohon

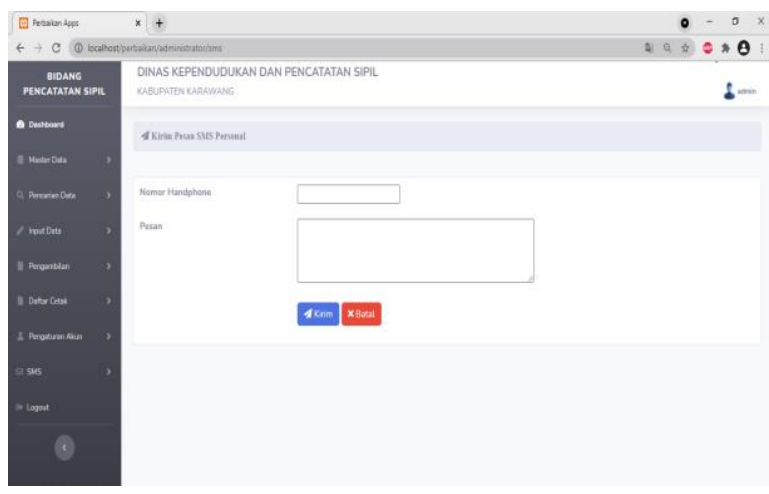

Gbr. 11 Halaman kirim SMS

10. Halaman preview cetak resi

Halaman preview cetak resi digunakan untuk melihat data resi sebelum di cetak

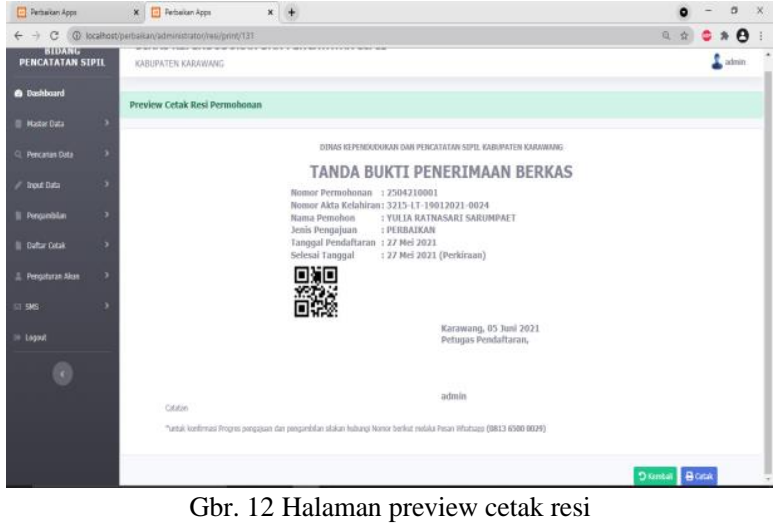

11. Halaman cetak laporan berdasarkan tanggal Halaman cetak laporan berdasarkan tanggal digunakan untuk mencetak laporan permohonan berdasarkan tanggal

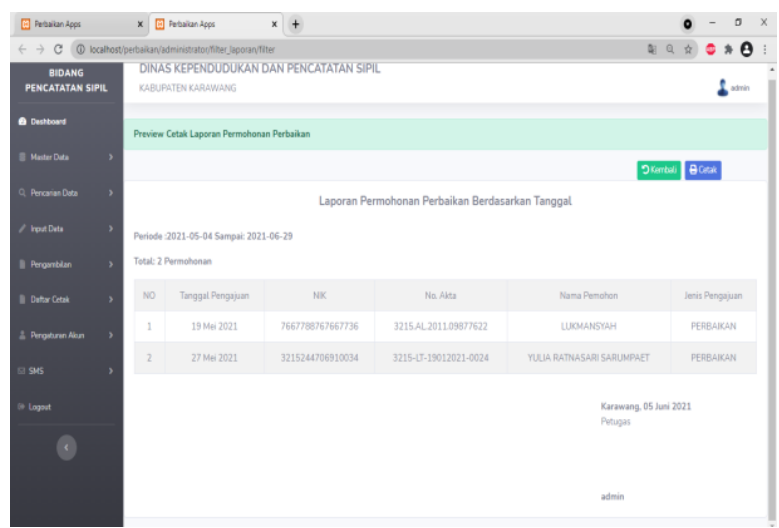

GBr. 13 Halaman cetak laporan berdasarkan tanggal

12. Halaman cetak laporan berdasarkan bulan Halaman cetak laporan berdasarkan tanggal digunakan untuk mencetak laporan permohonan berdasarkan bulan

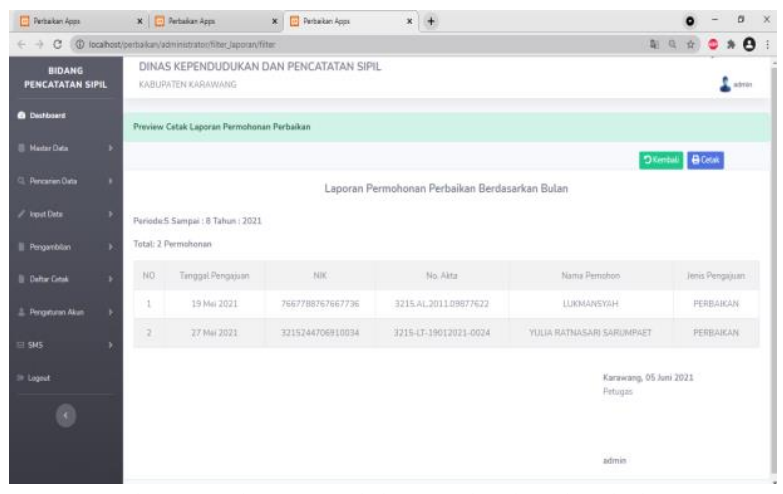

Gbr. 14 Halaman cetak laporan berdasarkan bulan

13. Halaman cetak laporan berdasarkan tahun Halaman cetak laporan berdasarkan tanggal digunakan untuk mencetak laporan permohonan berdasarkan tahun 


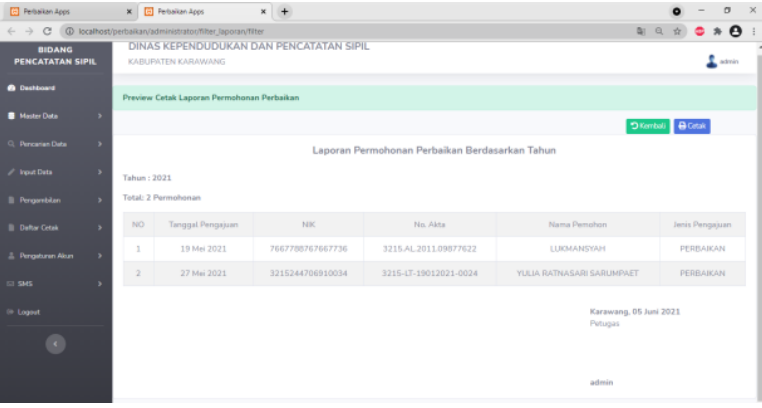

Gbr. 15 Halaman cetak laporan berdasarkan tahun

\section{Pengujian}

Pengujian adalah bagian yang terpenting dalam siklus pengembangan perangkat lunak. Pengujian dilakukan untuk mengetahui apa saja kelemahan yang terdapat pada perangkat lunak. Tujuan dari pengujian ini adalah untuk menjamin bahwa perangkat lunak yang dibangun memiliki kualitas yang baik. Pengujian perangkat lunak ini menggunakan metode pengujian black box. Pengujian black box ini tidak perlu tahu apa yang sesungguhnya terjadi dalam sistem perangkat lunak, yang diuji adalah masukan serta keluarannya, dengan berbagai masukan yang diberikan, apakah sistem atau perangkat lunak memberikan keluaran seperti apa yang kita harapkan atau tidak.

\section{Rencana Pengujian}

Pengujian aplikasi perbaikan akta kelahiran berbasis web ini menggunakan data uji berupa sebuah data masukan dari user.

TABEL I

PENGUJIAN HALAMAN USER

\begin{tabular}{|c|c|c|c|}
\hline No & $\begin{array}{l}\text { Requirement } \\
\text { yang di uji }\end{array}$ & Butir Uji & $\begin{array}{c}\text { Jenis } \\
\text { Pengujian }\end{array}$ \\
\hline 1 & Login User & $\begin{array}{l}\text { User melakukan login } \\
\text { kedalam sistem }\end{array}$ & Black Box \\
\hline 2 & $\begin{array}{l}\text { Input master } \\
\text { pemohon }\end{array}$ & $\begin{array}{l}\text { User melakukan input } \\
\text { data master pemohon }\end{array}$ & Black Box \\
\hline 3 & $\begin{array}{c}\text { Update master } \\
\text { pemohon }\end{array}$ & $\begin{array}{l}\text { User melakukan update } \\
\text { data master pemohon }\end{array}$ & Black Box \\
\hline 4 & $\begin{array}{l}\text { Hapus master } \\
\text { pemohon }\end{array}$ & $\begin{array}{l}\text { User melakukan hapus } \\
\text { data master pemohon }\end{array}$ & Black Box \\
\hline 5 & $\begin{array}{c}\text { Input } \\
\text { permohonan }\end{array}$ & $\begin{array}{c}\text { User melakukan input } \\
\text { data permohonan }\end{array}$ & Black Box \\
\hline 6 & $\begin{array}{c}\text { Update } \\
\text { permohonan }\end{array}$ & $\begin{array}{c}\text { User melakukan update } \\
\text { data permohonan }\end{array}$ & Black Box \\
\hline 7 & $\begin{array}{c}\text { Hapus } \\
\text { permohonan }\end{array}$ & $\begin{array}{c}\text { User melakukan hapus } \\
\text { data permohonan }\end{array}$ & Black Box \\
\hline 8 & $\begin{array}{c}\text { Input } \\
\text { pengambilan }\end{array}$ & $\begin{array}{c}\text { User melakukan input } \\
\text { data pengambilan }\end{array}$ & Black Box \\
\hline 9 & $\begin{array}{l}\text { Update data } \\
\text { pengambilan }\end{array}$ & $\begin{array}{c}\text { User melakukan update } \\
\text { data pengambilan }\end{array}$ & Black Box \\
\hline 10 & $\begin{array}{l}\text { Hapus Data } \\
\text { Pengambilan }\end{array}$ & $\begin{array}{c}\text { User melakukan Hapus } \\
\text { Data Pengambilan }\end{array}$ & Black Box \\
\hline 11 & Cari pemohon & $\begin{array}{c}\text { User melakukan } \\
\text { pencarian pemohon }\end{array}$ & Black box \\
\hline 12 & $\begin{array}{c}\text { Cari } \\
\text { permohonan }\end{array}$ & $\begin{array}{c}\text { User melakukan } \\
\text { pencarian permohonan }\end{array}$ & Black Box \\
\hline 13 & Kirim SMS & $\begin{array}{l}\text { User mengirim pesan } \\
\text { SMS }\end{array}$ & Black Box \\
\hline
\end{tabular}

TABEL II

PENGUJIAN HALAMAN ADMIN

\begin{tabular}{|c|c|c|c|}
\hline No & $\begin{array}{l}\text { Requirement } \\
\text { yang di uji }\end{array}$ & Butir Uji & $\begin{array}{c}\text { Jenis } \\
\text { Pengujian }\end{array}$ \\
\hline 1 & Login Admin & $\begin{array}{l}\text { Admin melakukan login } \\
\text { kedalam sistem }\end{array}$ & Black Box \\
\hline 2 & Input user & $\begin{array}{c}\text { Admin melakukan input } \\
\text { data user aplikasi }\end{array}$ & Black Box \\
\hline 3 & $\begin{array}{c}\text { Update data } \\
\text { user aplikasi }\end{array}$ & $\begin{array}{c}\text { Admin melakukan } \\
\text { update data user aplikasi }\end{array}$ & Black Box \\
\hline 4 & $\begin{array}{l}\text { Hapus data user } \\
\text { aplikasi }\end{array}$ & $\begin{array}{c}\text { Admin melakukan } \\
\text { hapus data user aplikasi }\end{array}$ & Black Box \\
\hline 5 & $\begin{array}{c}\text { Input data } \\
\text { layanan }\end{array}$ & $\begin{array}{c}\text { Admin melakukan input } \\
\text { data layanan }\end{array}$ & Black Box \\
\hline 6 & $\begin{array}{l}\text { Update data } \\
\text { layanan }\end{array}$ & $\begin{array}{l}\text { Admin melakukan } \\
\text { update data layanan }\end{array}$ & Black Box \\
\hline 7 & $\begin{array}{c}\text { Hapus data } \\
\text { layanan }\end{array}$ & $\begin{array}{l}\text { Admin melakukan } \\
\text { hapus data layanan }\end{array}$ & Black Box \\
\hline 8 & $\begin{array}{l}\text { input data } \\
\text { master } \\
\text { pemohon } \\
\end{array}$ & $\begin{array}{l}\text { admin melakukan input } \\
\text { data master pemohon }\end{array}$ & Black Box \\
\hline 9 & $\begin{array}{l}\text { Update data } \\
\text { master } \\
\text { pemohon }\end{array}$ & $\begin{array}{c}\text { Admin melakukan } \\
\text { update data master } \\
\text { pemohon }\end{array}$ & Black Box \\
\hline 10 & $\begin{array}{l}\text { Hapus data } \\
\text { master } \\
\text { pemohon }\end{array}$ & $\begin{array}{c}\text { Admin melakukan } \\
\text { update data master } \\
\text { pemohon } \\
\end{array}$ & Black Box \\
\hline 11 & $\begin{array}{l}\text { input data } \\
\text { permohonan }\end{array}$ & $\begin{array}{c}\text { admin melakukan input } \\
\text { data permohonan }\end{array}$ & Black box \\
\hline 12 & $\begin{array}{l}\text { Update data } \\
\text { permohonan }\end{array}$ & $\begin{array}{c}\text { Admin melakukan } \\
\text { update data permohonan }\end{array}$ & Black Box \\
\hline 13 & $\begin{array}{l}\text { Hapus data } \\
\text { permohonan }\end{array}$ & $\begin{array}{c}\text { Admin melakukan } \\
\text { hapus data permohonan }\end{array}$ & Black Box \\
\hline
\end{tabular}

Kasus dan Hasil Pengujian

Berikut beberapa kasus pengujian dan hasil dari pengujiannya:

1. Pengujian semua pada proses dan setelah login user

TABEL III

PENGUJIAN HALAMAN YANG DI AKSES USER

\begin{tabular}{|c|c|c|c|}
\hline Requirement & Skenario Uji & $\begin{array}{l}\text { Hasil yang } \\
\text { diharapkan }\end{array}$ & $\begin{array}{c}\text { Hasil } \\
\text { Pengujian }\end{array}$ \\
\hline \multirow[t]{2}{*}{ Login } & $\begin{array}{l}\text { Input login } \\
\quad \text { (jika benar) }\end{array}$ & $\begin{array}{l}\text { Tampilan } \\
\text { halaman } \\
\text { dashboard }\end{array}$ & Sesuai \\
\hline & $\begin{array}{l}\text { Input login } \\
\quad \text { (jika salah) }\end{array}$ & $\begin{array}{c}\text { Tampil } \\
\text { konfirmasi } \\
\text { login gagal }\end{array}$ & Sesuai \\
\hline \multirow[t]{2}{*}{$\begin{array}{l}\text { Input master } \\
\text { pemohon }\end{array}$} & $\begin{array}{l}\text { Input master } \\
\text { pemohon } \\
\text { (jika benar) }\end{array}$ & $\begin{array}{c}\text { Data } \\
\text { tersimpan dan } \\
\text { tampil } \\
\text { pemberitahuan } \\
\text { data tersimpan }\end{array}$ & Sesuai \\
\hline & $\begin{array}{l}\text { Input master } \\
\text { pemohon } \\
\text { (jika salah) }\end{array}$ & $\begin{array}{c}\text { Tampil } \\
\text { peringatan } \\
\text { pada setiap } \\
\text { kesalahan }\end{array}$ & Sesuai \\
\hline & $\begin{array}{l}\text { Update master } \\
\text { pemohon } \\
\text { \{jika benar) }\end{array}$ & $\begin{array}{l}\text { Data berhasil } \\
\text { di update dan } \\
\text { tampil } \\
\text { pemberitahuan }\end{array}$ & Sesuai \\
\hline
\end{tabular}




\begin{tabular}{|c|c|c|c|}
\hline \multirow{2}{*}{$\begin{array}{c}\text { Update } \\
\text { master } \\
\text { pemohon }\end{array}$} & & $\begin{array}{c}\text { data berhasil } \\
\text { diupdate }\end{array}$ & \\
\hline & $\begin{array}{l}\text { Update master } \\
\text { pemohon } \\
\quad \text { (jika salah) }\end{array}$ & $\begin{array}{c}\text { Tampil } \\
\text { peringatan } \\
\text { pada setiap } \\
\text { kesalahan }\end{array}$ & Sesuai \\
\hline \multirow[t]{2}{*}{$\begin{array}{l}\text { Hapus } \\
\text { master } \\
\text { pemohon }\end{array}$} & $\begin{array}{l}\text { Hapus master } \\
\text { pemohon } \\
\text { (jika benar) }\end{array}$ & $\begin{array}{c}\text { Data berhasil } \\
\text { di hapus }\end{array}$ & \multirow[t]{2}{*}{ Sesua } \\
\hline & $\begin{array}{l}\text { Hapus master } \\
\text { pemohon } \\
\text { (jika salah) }\end{array}$ & $\begin{array}{c}\text { Tampil pesan } \\
\text { error }\end{array}$ & \\
\hline \multirow[t]{2}{*}{$\begin{array}{l}\text { Input } \\
\text { permohonan }\end{array}$} & $\begin{array}{l}\text { Input permohonan } \\
\text { (jika benar) }\end{array}$ & $\begin{array}{c}\text { Data } \\
\text { tersimpan dan } \\
\text { tampil } \\
\text { pemberitahuan } \\
\text { data tersimpan }\end{array}$ & \multirow[t]{2}{*}{ Sesuai } \\
\hline & $\begin{array}{l}\text { Input permohonan } \\
\text { (jika salah) }\end{array}$ & $\begin{array}{c}\text { Tampil } \\
\text { peringatan } \\
\text { pada setiap } \\
\text { kesalahan }\end{array}$ & \\
\hline \multirow[t]{2}{*}{$\begin{array}{l}\text { Update } \\
\text { permohonan }\end{array}$} & $\begin{array}{l}\text { Update } \\
\text { permohonan } \\
\text { \{jika benar) }\end{array}$ & $\begin{array}{l}\text { Data berhasil } \\
\text { di update dan } \\
\text { tampil } \\
\text { pemberitahuan } \\
\text { data berhasil } \\
\text { diupdate }\end{array}$ & \multirow[t]{2}{*}{ Sesuai } \\
\hline & $\begin{array}{l}\text { Update master } \\
\text { pemohon } \\
\text { (jika salah) }\end{array}$ & $\begin{array}{c}\text { Tampil } \\
\text { peringatan } \\
\text { pada setia } \\
\text { kesalahan }\end{array}$ & \\
\hline \multirow[t]{2}{*}{$\begin{array}{l}\text { Hapus } \\
\text { permohonan }\end{array}$} & $\begin{array}{l}\text { Hapus } \\
\text { permohonan } \\
\text { (jika benar) }\end{array}$ & $\begin{array}{c}\text { Data berhasil } \\
\text { di hapus }\end{array}$ & \multirow[t]{2}{*}{ Sesuai } \\
\hline & $\begin{array}{l}\text { Hapus } \\
\text { permohonan } \\
\text { (jika salah) }\end{array}$ & $\begin{array}{l}\text { Tampil pesan } \\
\text { error }\end{array}$ & \\
\hline \multirow[t]{2}{*}{$\begin{array}{l}\text { Input data } \\
\text { pengambilan }\end{array}$} & $\begin{array}{l}\text { Input data } \\
\text { pengambilan } \\
\text { (jika benar) }\end{array}$ & $\begin{array}{c}\text { Data } \\
\text { tersimpan dan } \\
\text { tampil } \\
\text { pemberitahuan } \\
\text { data tersimpan }\end{array}$ & \multirow[t]{2}{*}{ Sesuai } \\
\hline & $\begin{array}{l}\text { Input data } \\
\text { pengambilan } \\
\text { (jika salah) }\end{array}$ & $\begin{array}{c}\text { Tampil } \\
\text { peringatan } \\
\text { pada setiap } \\
\text { kesalahan }\end{array}$ & \\
\hline \multirow[t]{2}{*}{$\begin{array}{l}\text { Update data } \\
\text { pengambilan }\end{array}$} & $\begin{array}{l}\text { Update data } \\
\text { pengambilan } \\
\text { \{jika benar) }\end{array}$ & $\begin{array}{l}\text { Data berhasil } \\
\text { di update dan } \\
\text { tampil } \\
\text { pemberitahuan } \\
\text { data berhasil } \\
\text { diupdate }\end{array}$ & \\
\hline & $\begin{array}{l}\text { Update data } \\
\text { pengambilan } \\
\text { (jika salah) }\end{array}$ & $\begin{array}{c}\text { Tampil } \\
\text { peringatan } \\
\text { pada setia } \\
\text { kesalahan }\end{array}$ & \\
\hline \multirow{2}{*}{$\begin{array}{l}\text { Hapus data } \\
\text { pengambilan }\end{array}$} & $\begin{array}{l}\text { Hapus data } \\
\text { pengambilan } \\
\text { (jika benar) }\end{array}$ & $\begin{array}{c}\text { Data berhasil } \\
\text { di hapus }\end{array}$ & \multirow[t]{2}{*}{ Sesuai } \\
\hline & $\begin{array}{l}\text { Hapus data } \\
\text { pengambilan } \\
\text { (jika salah) }\end{array}$ & $\begin{array}{l}\text { Tampil pesan } \\
\text { error }\end{array}$ & \\
\hline
\end{tabular}

\begin{tabular}{|c|c|c|c|}
\hline \multirow{2}{*}{$\begin{array}{l}\text { Cari } \\
\text { pemohon }\end{array}$} & $\begin{array}{l}\text { Cari pemohon } \\
\text { (jika benar) }\end{array}$ & $\begin{array}{c}\text { Tampil data } \\
\text { pemohon yang } \\
\text { di cari }\end{array}$ & \multirow[t]{2}{*}{ Sesuai } \\
\hline & $\begin{array}{l}\text { Cari pemohon } \\
\text { (jika gagal) }\end{array}$ & $\begin{array}{c}\text { Tampil } \\
\text { konfirmasi } \\
\text { data tidak } \\
\text { ditemukan }\end{array}$ & \\
\hline \multirow{2}{*}{$\begin{array}{l}\text { Cari } \\
\text { permohonan }\end{array}$} & $\begin{array}{l}\text { Cari permohonan } \\
\text { (jika benar) }\end{array}$ & $\begin{array}{c}\text { Tampil data } \\
\text { pemohon yang } \\
\text { di cari }\end{array}$ & Sesuai \\
\hline & $\begin{array}{l}\text { Cari permohonan } \\
\text { (jika gagal) }\end{array}$ & $\begin{array}{c}\text { Tampil } \\
\text { konfirmasi } \\
\text { data tidak } \\
\text { ditemukan }\end{array}$ & \\
\hline \multirow[t]{2}{*}{ Kirim SMS } & $\begin{array}{l}\text { Kirim SMS } \\
\text { (jika benar) }\end{array}$ & $\begin{array}{l}\text { SMS berhasil } \\
\text { terkirim dan } \\
\text { tampil } \\
\text { pemberitahuan } \\
\text { SMS berhasil } \\
\text { terkirim }\end{array}$ & \multirow[t]{2}{*}{ Sesuai } \\
\hline & $\begin{array}{l}\text { Kirim SMS } \\
\text { (jika salah) }\end{array}$ & $\begin{array}{c}\text { SMS Gagal } \\
\text { terkirim dan } \\
\text { tampil } \\
\text { pemberitahuan } \\
\text { SMS gagal } \\
\text { terkirim }\end{array}$ & \\
\hline
\end{tabular}

Kesimpulan Hasil pengujian

Berdasarkan hasil pengujian dengan kasus uji sampel diatas dapat ditarik kesimpulan bahwa perangkat lunak secara fungsional mengeluarkan hasil sesuai dengan yang diharapkan.

\section{PENUTUP}

\section{Kesimpulan}

Berdasarkan penelitian yang dilakukan oleh penulis pada Dinas Kependudukan dan pencatatan sipil Kabupaten Karawang maka penulis mengambil kesimpulan sebagai berikut :

1. Aplikasi perbaikan akta kelahiran berbasis web yang dibuat penulis dapat mempermudah proses pelayanan perbaikan akta kelahiran, petugas dapat dengan mudah membuat laporan permohonan perbaikan berdasarkan tanggal, bulan dan tahun

2. Dengan menggunakan SMS Gateway penyampaian informasi menjadi lebih cepat sampai kepada pemohon tentang status permohonan perbaikan akta kelahiran.

3. Aplikasi perbaikan akta kelahiran memiliki menu pelacakan status permohonan sehingga dapat mempermudah petugas dalam melacak status permohonan perbaikan. 
Saran

Berdasarkan hasil penelitian yang dilakukan, maka penulis mencoba memberikan saran-saran yang diharapkan dapat berguna bagi pihak instansi dan pihak-pihak yang membutuhkan, adapun saran-saran Page | 229 yang penulis berikan sebagai berikut:

1. Diperlukan adanya pengembangan sistem ini secara berkala dan mengintegrasikan aplikasi perbaikan akta kelahiran ini dengan database Dinas kependudukan dan Pencatatan Sipil Kabupaten Karawang.

2. Di adakan pelatihan secara berkala kepada pegawai yang belum bisa mengoperasikan komputer agar program yang diusulkan dapat digunakan secara maksimal.

3. Perlunya penyebaran informasi dan edukasi kepada masyarakat perihal tata cara pengajuan perbaikan dan persyaratan perbaikan akta kelahiran sehingga masyarakat tidak kesulitan dalam mengajukan permohonan perbaikan akta kelahiran.

\section{DAFTAR PUSTAKA}

[1] M. Alda, Rekayasa Perangkat Lunak Berorientasi Objek. 2021.

[2] R. A. Rusli. Ahmar, Ansari Saleh, Pemrograman Website dengan PHP-MySQL untuk pemula. 2012.

[3] B. Raharjo, Belajar Otodidak Framework CodeIgniter. Bandung: Informatika. Bandung: Informatika, 2015.

[4] A. Basuki, Membangun Aplikasi SMS Gateway berbasis Web dengan Codeingniter dan Bootstrap. Yogyakarta: Lokomedia, 2019.

[5] R. s Pressman, Software Engineering: A Practitioner's Approach. 2014.

[6] B. Rumpe, Agile Modeling with UML. 2017

[7] B. Unhelkar, Software engineering with UML. 2017. 